\title{
OTIMIZAÇÃO DO PROCESSO DE PELOTIZAÇÃO ATRAVÉS DA SELEÇÃO ADEQUADA DE COMBUSTÍVEIS SÓLIDOS*
}

\author{
Janaina Gonçalves Maria da Silva Machado ${ }^{1}$ \\ Lorena da Costa Nascimento 2 \\ Silvio Maranha ${ }^{2}$ \\ Marcus Emrich ${ }^{2}$ \\ Washington Mafra ${ }^{2}$ \\ Raquel Pereira ${ }^{2}$
}

\section{Resumo}

O antracito é um dos tipos de combustíveis utilizados no processo de pelotização. Estudos de caracterização desses materiais realizados no CTF-Vale indicaram muitos casos de antracitos contaminados com carvões betuminosos. O objetivo desse estudo é avaliar como essa contaminação pode afetar a qualidade das pelotas queimadas e também o manuseio desses combustíveis. Para este desenvolvimento alguns antracitos, com diferentes níveis de contaminação, foram caracterizados química, física, petrográfica e mineralogicamente e seus desempenhos foram avaliados em plantas piloto de pelotização. De acordo com os resultados, quanto maior o grau de contaminação de antracitos com carvões minerais pior a qualidade física das pelotas queimadas. Em casos extremos, quando os antracitos foram contaminados com maiores teores de carvões alto-voláteis as pelotas se desintegraram durante os pot grate tests. Observou-se também que a contaminação afeta negativamente os principais parâmetros que influenciam o manuseio de combustíveis, que são umidade, distribuição granulométrica e composição mineralógica.

Palavra-chave: Pelotização; Antracito; Contaminação; Carvão mineral.

\section{PELLETIZING PROCESS OPTIMIZATION THROUGH PROPER SELECTION OF SOLID FUELS}

\begin{abstract}
One type of fuel used in the process is anthracite and studies of characterization done at CTF Vale have shown many cases of fuels contaminated with coals. This study focus on evaluation how the contamination of anthracites with coals can affect the quality of the fired pellets and also, how it can affect the fuel handling in the pelletizing plants. For this development some anthracites, with different levels of contamination, were chemical, physical, petrographic and mineralogical characterized and their performance were evaluated in pelletizing pilot plants. According to results, the greater the contamination degree of anthracites with coals the worst was physical quality of fired pellets. In extreme cases, when the anthracites were contaminated with high amount of volatile coals, pellets disintegrated during pot grate tests. Besides, it was observed that the contamination also affects negatively the main parameters that have an effect on fuel handling, that are moisture, size distribution and mineralogical composition.
\end{abstract}

Keywords: Pelletizing; Anthracite; Contamination; Mineral coal.

Centro de Tecnologia de Ferrosos, Vale S.A., Belo Horizonte, MG, Brasil.

2 Diretoria de Pelotização, Vale S.A., Vitória, ES, Brasil.

* Contribuição técnica ao 44 Seminário de Redução de Minério de Ferro e Matérias-primas, 15ำ Simpósio Brasileiro de Minério de Ferro e 2o Simpósio Brasileiro de Aglomeração de Minério de Ferro, 15 a 18 de setembro de 2014, Belo Horizonte, MG, Brasil. 


\section{INTRODUÇÃO}

No processo de pelotização do minério de ferro, importantes insumos são utilizados os quais afetam a qualidade física das pelotas queimadas e, consequentemente, a produtividade das plantas. Dentre estes insumos, tem-se o combustível sólido.

O combustível sólido é usado, em mistura com o minério e fundentes, como fonte energética de menor custo na produção das pelotas de minério de ferro, de forma a reduzir o consumo de óleo combustível no forno. Além de ser um importante fator energético, o combustível sólido proporciona uma melhor distribuição de calor na pelota durante a etapa de queima contribuindo para uma melhoria na qualidade física da pelota, assim como aumento de produtividade do processo. Ele também contribui na formação de poros nas pelotas em virtude da liberação de gás durante a queima.

Alguns trabalhos na literatura já abordaram o efeito da granulometria e dosagem do combustível sólido na qualidade das pelotas (1 e 2). A influência de diversos tipos de combustíveis sólidos foi avaliada por Casagrande et. al $2008^{3}$. Nesse trabalho, combustíveis com diferentes características químicas, petrográficas e de reatividade, como carvões alto, médio e baixo voláteis, antracitos, coques de petróleo e coke breeze foram testados, mas sem nenhum tipo de restrição. Foi visto que combustíveis de baixo rank (carvões) tiveram um forte impacto negativo na qualidade da pelota, sendo que o maior impacto observado foi nas propriedades físicas das pelotas.

Para não afetar negativamente a qualidade física da pelota queimada, o combustível sólido usado na pelotização necessita ter um apropriado perfil de combustão, o que se tenta obter por meio da especificação do material volátil (MV). Um dos combustíveis mais usados no processo são os antracitos. Coque de petróleo e coke breeze também possuem características químicas adequadas para serem utilizados.

No entanto, o que tem se percebido na prática é que alguns combustíveis sólidos, mesmo que atendendo a todas as especificações, principalmente a relacionada ao MV volátil, não tem apresentado bom desempenho nas plantas de pelotização da Vale.

Estudos de caracterização realizados no Centro de Tecnologia de Ferrosos da Vale, usando técnicas não usuais de caracterização como análise petrográfica e térmica tem mostrado que em muitos casos os antracitos usados na pelotização estão contaminados com teores consideráveis de carvão mineral ${ }^{4}$. O grau de contaminação tem sido tal, que tais combustíveis podem ser considerados na verdade como misturas de antracito/carvão.

O objetivo desse trabalho é avaliar o efeito da contaminação dos antracitos com carvões minerais, com a restrição de controle do $\mathrm{MV}$, sobre a qualidade física das pelotas queimadas e, também, na operação de manuseio nas plantas de pelotização.

\section{MATERIAIS E MÉTODOS}

Todo o trabalho foi executado no Centro de Tecnologia de Ferrosos da Vale em Nova Lima, Minas Gerais.

\subsection{Efeito da Contaminação dos Antracitos com Carvões Minerais na Qualidade Física das Pelotas}

Os antracitos puros usados foram denominados como $\mathrm{A} 1$ e $\mathrm{A} 2 \mathrm{com}$, respectivamente, 7,89 e $11,65 \%$ de matéria volátil. Esses antracitos foram misturados com carvões minerais alto e médio voláteis, de tal forma que se gerou seis tipos de misturas com diferentes níveis de contaminação. O teor de matéria volátil das misturas variou de 12 a $17 \%$, sendo que para cada teor de MV foram geradas duas misturas, uma com alta

* Contribuição técnica ao 44ํ Seminário de Redução de Minério de Ferro e Matérias-primas, 15ำ Simpósio Brasileiro de Minério de Ferro e $2^{\circ}$ Simpósio Brasileiro de Aglomeração de Minério de Ferro, 15 a 18 de setembro de 2014, Belo Horizonte, MG, Brasil. 
contaminação (AC) e outra com baixa contaminação (BC). Algumas das características dos antracitos puros e misturas são apresentadas na Tabela 1.

Tabela 1 - Antracitos e misturas de antracito com carvão mineral usados na avaliação do efeito da contaminação na qualidade física das pelotas

\begin{tabular}{|c|c|c|c|c|c|c|c|c|}
\hline Amostras & $\begin{array}{c}\text { Antracito } \\
\mathrm{A} 1\end{array}$ & $\begin{array}{c}\text { Antracito } \\
\mathrm{A} 2\end{array}$ & $\begin{array}{c}\text { Mistura } \\
1\end{array}$ & $\begin{array}{c}\text { Mistura } \\
2\end{array}$ & $\begin{array}{c}\text { Mistura } \\
3\end{array}$ & $\begin{array}{c}\text { Mistura } \\
4\end{array}$ & $\begin{array}{c}\text { Mistura } \\
5\end{array}$ & $\begin{array}{c}\text { Mistura } \\
6\end{array}$ \\
\hline $\begin{array}{c}\text { Teor de MV } \\
(\%)\end{array}$ & 7,89 & 11,65 & 12,59 & 12,95 & 15,04 & 14,46 & 17,63 & 17,65 \\
\hline $\begin{array}{c}\text { Nível de } \\
\text { contaminação }\end{array}$ & $\mathrm{SC}$ & $\mathrm{SC}$ & $\mathrm{AC}$ & $\mathrm{BC}$ & $\mathrm{AC}$ & $\mathrm{BC}$ & $\mathrm{AC}$ & $\mathrm{BC}$ \\
\hline
\end{tabular}

SC: Sem contaminação com carvões minerais; BC: Baixa Contaminação; AC: Alta contaminação.

As amostras de combustíveis foram caracterizadas por meio das seguintes análises:

- análise imediata: cinzas, matéria volátil e carbono fixo (por diferença);

- análise petrográfica: poder refletor da vitrinita e desvio padrão;

- análise termogravimétrica: Tc - temperatura na qual a perda de massa por aquecimento compensa o ganho de massa devido à quimissorção à temperaturas baixas; Ti - temperatura de início da combustão, temperatura na qual a perda de massa é $20 \%$ da perda máxima ${ }^{5} ; \mathrm{Tp}$ - temperatura em que há o máximo de reatividade; Tf temperatura final de combustão.

A localização destas informações de temperatura e da reatividade em um perfil de combustão típico é mostrada na Figura 1. Os experimentos foram conduzidos sob as seguintes condições: aproximadamente $30 \mathrm{mg}$ de cada amostra foram aquecidas entre $50^{\circ} \mathrm{C}$ e $1000^{\circ} \mathrm{C}$ a uma taxa de $15^{\circ} \mathrm{C} / \mathrm{min}$ usando fluxo de ar $(50 \mathrm{ml} / \mathrm{min})$. O máximo de reatividade e/ou a taxa máxima de reação $(\mathrm{Rp})$ das amostras foi avaliada de acordo com a equação mostrada na Figura 1.

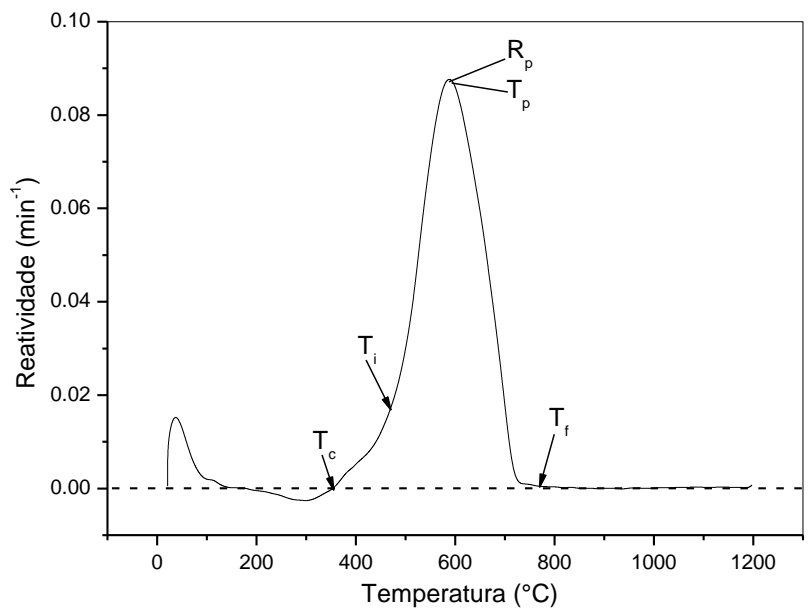

$$
R_{p}=1 / m_{0}(d m / d t)
$$

mo: massa inicial da amostra isenta de cinzas; $d m / d t$ : variação da perda de massa no instante de tempo t; Rp: reatividade do combustível ao ar, em base seca e isenta de cinzas

Figura 1 - Perfil de combustão típico com as temperaturas características e equação usada para cálculo da $\mathrm{Rp}$

Para a realização dos testes em pot grate, as amostras de combustíveis foram misturadas com uma amostra padrão de pellet feed de Tubarão destinado à produção de pelota para alto-forno, mas sempre considerando um teor de carbono fixo constante e igual a $1,05 \%$. Da mesma forma, foram mantidos constantes, o perfil de queima dos testes em pot grate e a basicidade binária das pelotas pela adição de calcário calcítico. O teste físico realizado para avaliar a qualidade da pelota queimada foi o da resistência à compressão (norma ISO 4700) [6]. 
F

\subsection{Efeito da Contaminação dos Antracitos com Carvões Minerais no Manuseio}

Para avaliação do efeito da contaminação dos antracitos com carvões minerais no manuseio foram investigadas duas amostras de combustíveis provenientes da usina de pelotização e que atendiam à especificação de qualidade da pelotização. São elas:

- Antracito A (referência)

- Antracito B

As amostras foram submetidas às seguintes técnicas de caracterização:

- Análise petrográfica: poder refletor da vitrinita;

- Umidade: Superficial, Inerente e Total;

- Análise Imediata: cinzas, matéria volátil e carbono fixo (por diferença);

- Análise Física: HGl;

- Análise granulométrica

- Difração de Raios-X dos antracitos in natura e das cinzas em diferentes faixas granulométricas. Para estas análises, as amostras foram pulverizadas abaixo de $0,045 \mathrm{~mm}$. Os difratogramas foram obtidos no intervalo de $10-70^{\circ}$ (20), num passo de 0,02 e tempo de $1 \mathrm{~s}$ em cada passo. As fases cristalinas foram identificadas e interpretadas usando software Jade.

\section{RESULTADOS E DISCUSSÃO}

\subsection{Efeito da Contaminação dos Antracitos com Carvões Minerais na Qualidade Física das Pelotas}

Os perfis petrográficos com os parâmetros de refletância da vitrina e desvio padrão, bem como a análise imediata das amostras de combustíveis são mostrados na Figura 2.

Observa-se na Figura 2 que:

- O antracito puro A1 apresentou 2 (duas) populações distintas. A primeira população (cerca de $70 \%$ ) com valores de refletância mais baixa que variaram de 2,5-3,8\% Rrandom, que é característico de antracito, e a segunda população (cerca de 30\%) com valores mais elevados de refletância, de 4,4 até 5,5\% Rrandom, indicando um rank de meta-antracito. $\mathrm{O}$ alto desvio padrão encontrado $(0,73)$ deveu-se à presença destas duas populações.

- O antracito puro A2 apresentou apenas uma população de vitrinitas com um range que variou de 1,8 a 2,4\% Rrandom que é característico de semi-antracito. Pelo fato dessa amostra conter apenas semi-antracito, o desvio padrão encontrado foi baixo $(0,12)$.

- As misturas 1 e 2, 3 e 4, 5 e 6, apesar de cada par ter MV semelhante, apresentaram composições petrográficas bem diferentes, o que se refletiu no desvio padrão, que sempre foi menor para as misturas com baixas contaminações (2, 4 e 6$)$. 


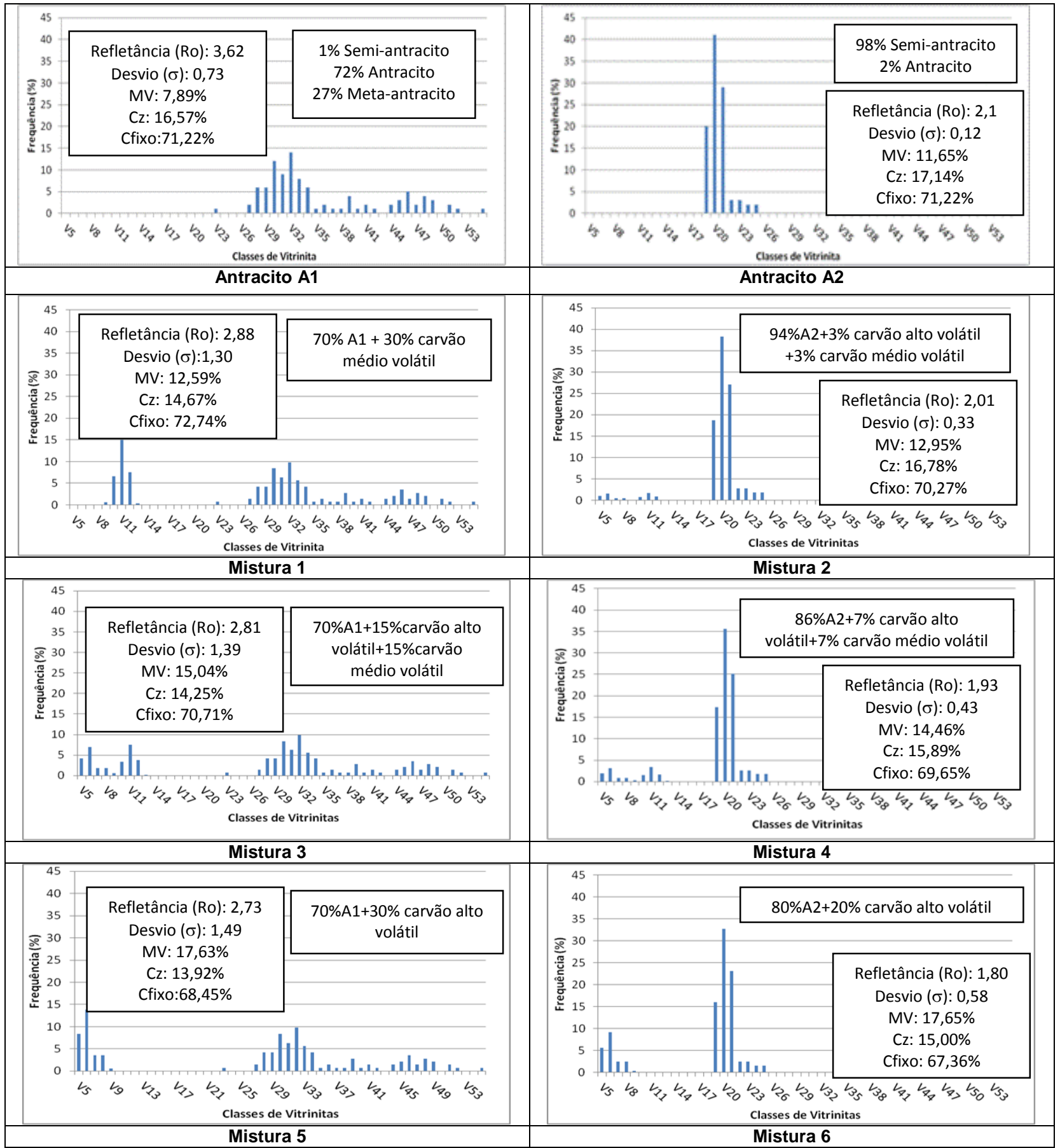

Figura 2 - Perfis petrográficos e análise imediata dos combustíveis

Os resultados obtidos dos perfis de combustão e as temperaturas características das diferentes amostras de combustíveis estão mostrados na Tabela 2 e Figuras 3 e 4. 


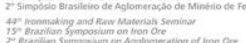

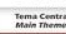

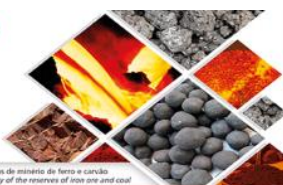

Tabela 2 - Dados comparativos de reatividade máxima e temperaturas características na combustão das amostras de combustíveis.

\begin{tabular}{|c|c|c|c|c|c|}
\hline Amostra & $\mathrm{Ti}\left({ }^{\circ} \mathrm{C}\right)$ & $\mathrm{Tf}\left({ }^{\circ} \mathrm{C}\right)$ & $\mathrm{Tp}\left({ }^{\circ} \mathrm{C}\right)$ & $\mathrm{Rp}\left(\mathrm{min}^{-1}\right)$ & $\mathrm{Tf}-\mathrm{Ti}$ \\
\hline $\mathrm{A} 1$ & 526 & 755 & 623 & 0,0948 & 229 \\
\hline $\mathrm{A} 2$ & 462 & 722 & 577 & 0,0961 & 260 \\
\hline Mistura 1 & 478 & 759 & 610 & 0,0844 & 281 \\
\hline Mistura 2 & 452 & 719 & 586 & 0,0892 & 267 \\
\hline Mistura 3 & 455 & 748 & 603 & 0,0827 & 293 \\
\hline Mistura 4 & 447 & 716 & 578 & 0,0878 & 269 \\
\hline Mistura 5 & 434 & 756 & 614 & 0,0788 & 322 \\
\hline Mistura 6 & 428 & 707 & 569 & 0,0866 & 279 \\
\hline
\end{tabular}

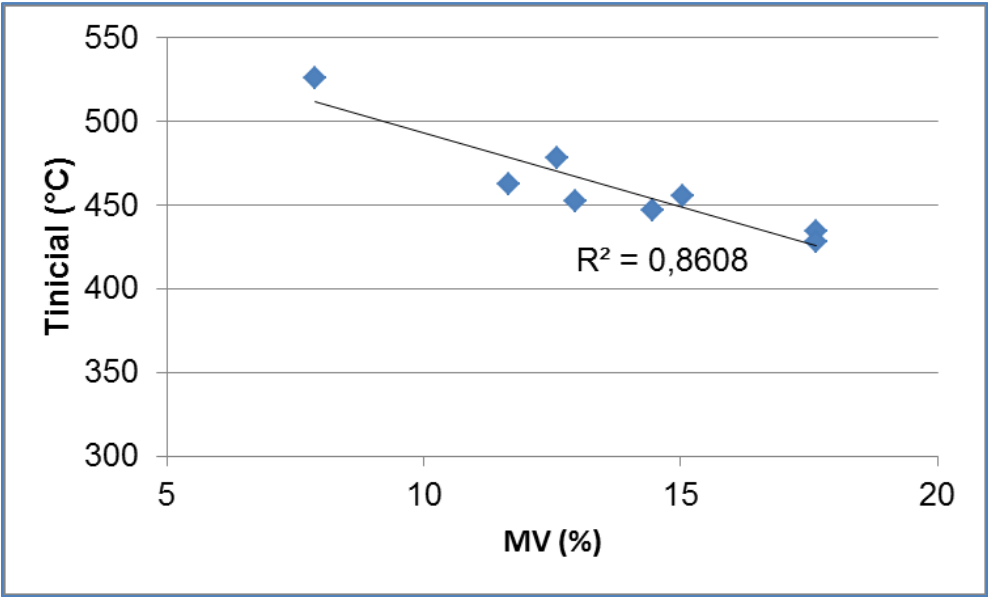

Figura 3 - Relação entre temperatura inicial de queima e MV das amostras de combustíveis.

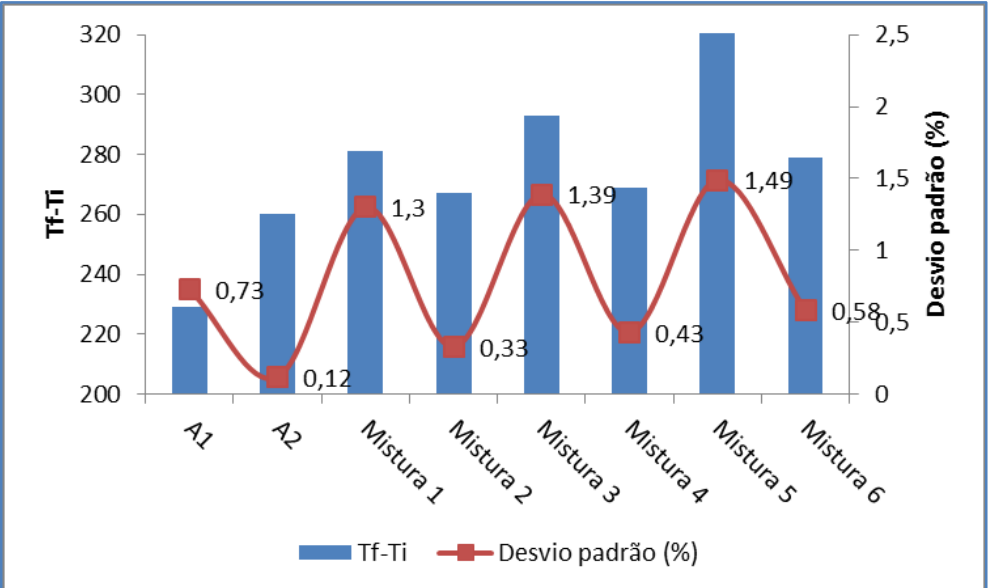

Figura 4 - Relação entre o intervalo de combustão com o desvio padrão da análise petrográfica das amostras de combustíveis

Nota-se na Figura 3 que a MV se correlacionou bem com a temperatura inicial da combustão obtida em termobalança e que, de uma forma geral, quanto maior foi a MV, menor foi a temperatura inicial de combustão ou mais cedo começou a queima do combustível. Na Figura 4 pode ser visto que o antracito A1 com menor teor de MV e sem a presença de contaminantes teve um intervalo de combustão consideravelmente

* Contribuição técnica ao 44ำ Seminário de Redução de Minério de Ferro e Matérias-primas, 15ำ Simpósio Brasileiro de Minério de Ferro e 2o Simpósio Brasileiro de Aglomeração de Minério de Ferro, 15 a 18 de setembro de 2014, Belo Horizonte, MG, Brasil. 
menor $\left(229^{\circ} \mathrm{C}\right)$ em relação aos outros combustíveis. Além disto, observa-se claramente que, para um mesmo teor de MV do antracito, quanto maior foi o desvio padrão da refletância, maior foi o intervalo de combustão.

A Tabela 3 mostra a resistência à compressão das pelotas queimadas para as diferentes amostras de combustíveis.

Tabela 3 - Resistência à compressão das pelotas para as diferentes amostras de combustíveis.

\begin{tabular}{|c|c|c|c|c|c|c|c|c|}
\hline Amostra & A1 & A2 & $\begin{array}{c}\text { Mistura } \\
1\end{array}$ & $\begin{array}{c}\text { Mistura } \\
2\end{array}$ & $\begin{array}{c}\text { Mistura } \\
3\end{array}$ & $\begin{array}{c}\text { Mistura } \\
4\end{array}$ & $\begin{array}{c}\text { Mistura } \\
5\end{array}$ & $\begin{array}{c}\text { Mistura } \\
6\end{array}$ \\
\hline $\begin{array}{c}\text { RC } \\
\text { (daN/p) }\end{array}$ & 275 & 257 & 229 & 263 & $*$ & 251 & $*$ & 258 \\
\hline
\end{tabular}

*Ocorreu desintegração das pelotas.

A pelota queimada com o antracito $A 1$, sem contaminação com carvões minerais e com menor teor de matéria volátil, apresentou o maior valor de resistência à compressão. Quando do uso do antracito A2 (apesar de puro, porém com maior teor de matéria volátil) ocorreu uma diminuição significativa da resistência da pelota. Em relação às misturas, nota-se que as pelotas que apresentaram melhor desempenho foram aquelas em que misturas de combustíveis com baixa contaminação foram usadas, sendo que as de alta contaminação e maior teor de MV (15 e 17\%) nem suportaram a condição de processamento térmico adotada e se desintegraram com graves consequências ao processo.

Nas Figuras 5 e 6 são mostradas as correlações entre os parâmetros térmicos e petrográficos das diferentes amostras de combustíveis e a resistência à compressão das pelotas.

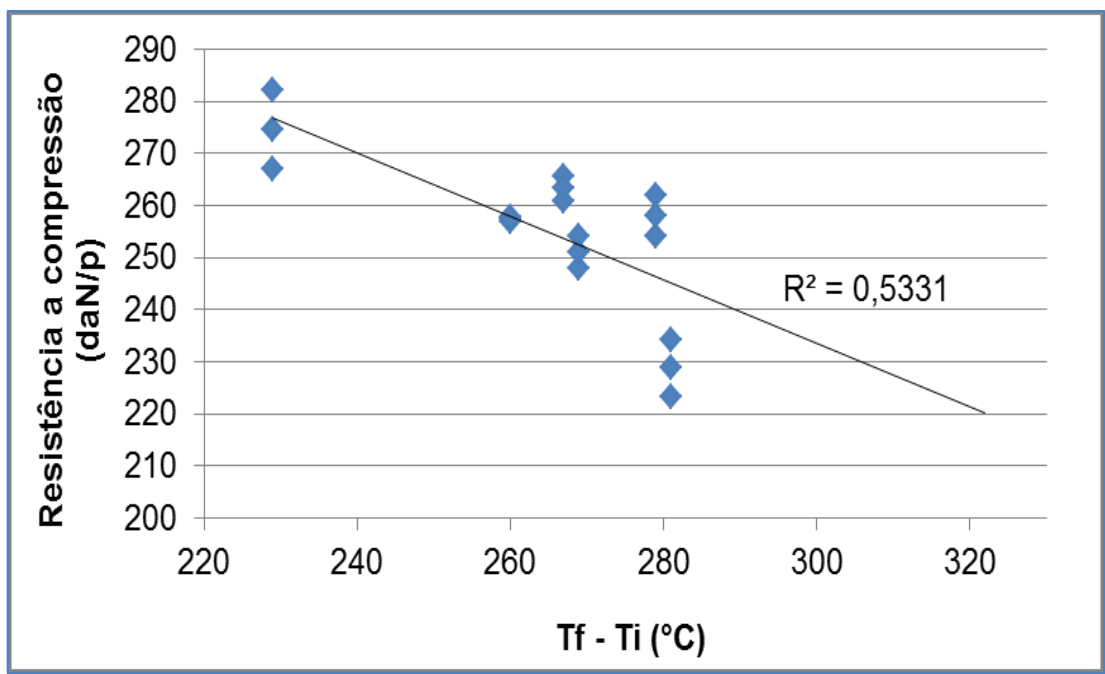

Figura 5 - Correlação entre a resistência à compressão e o intervalo de combustão das amostras de combustíveis

* Contribuição técnica ao 44ํㅗㄴ Seminário de Redução de Minério de Ferro e Matérias-primas, 15 Simpósio Brasileiro de Minério de Ferro e 2º Simpósio Brasileiro de Aglomeração de Minério de Ferro, 15 a 18 de setembro de 2014, Belo Horizonte, MG, Brasil. 


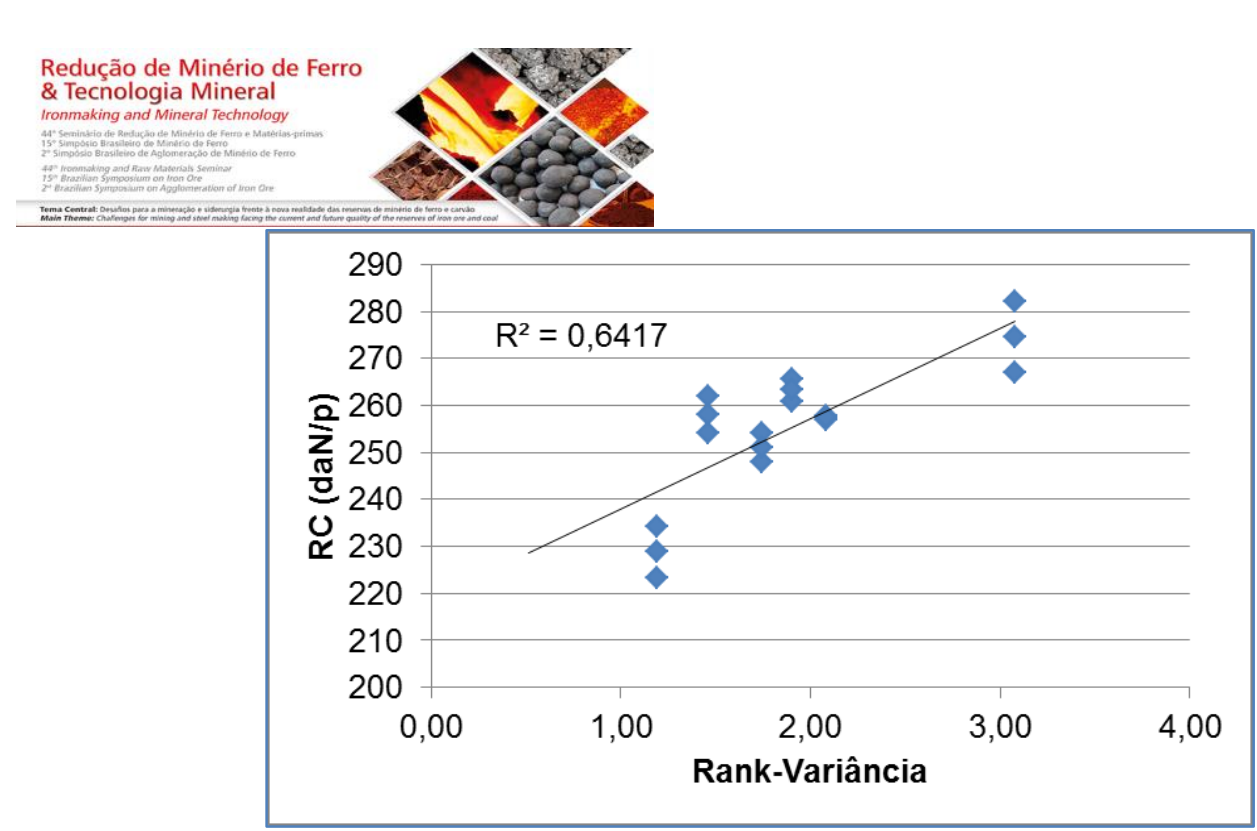

Figura 6 - Correlação entre a resistência à compressão e a relação rank-variância das amostras de combustíveis

Na Figura 5, pode ser visto que há uma forte indicação de que a resistência à compressão das pelotas possua uma correlação inversa com o intervalo de combustão obtido via análise termogravimétrica. Quanto maior o grau de contaminação dos antracitos, maior foi o intervalo de combustão e menor a resistência da pelota.

$\mathrm{Na}$ Figura 6, pode ser observado que a resistência à compressão possui boa correlação com os parâmetros petrográficos rank e desvio padrão. A análise de rank é uma análise de média, portanto, decidiu-se fazer uma relação entre o rank e sua variância. A variância estabelece os desvios em relação à média (Variância = Desvio Padrão²). Quanto maior o rank (maior quantidade de antracitos e meta-antracitos) e quanto menor o desvio padrão (menor nível de contaminação) maior foi a resistência da pelota.

Uma correlação múltipla entre a resistência à compressão e as características do combustível que parecem estar relacionadas ao seu comportamento durante a queima, MV e rank-variância, não pode ser obtida em função do pequeno banco de dados disponível.

\subsection{Efeito da Contaminação dos Antracitos com Carvões Minerais no Manuseio}

As Tabelas 4 a 6 apresentam, respectivamente, os resultados das análises petrográficas, físicas e químicas das amostras de combustíveis analisadas, e a Figura 7, as distribuições granulométricas das mesmas.

Tabela 4 - Análise petrográfica das amostras de combustíveis

\begin{tabular}{|c|c|c|}
\hline Amostra & $\mathrm{Rr}_{\text {médio }} \%$ & Composição \%vol \\
\hline & & $6 \%$ HVB B/A \\
A & 2,83 & $5,6 \%$ MVB/LVB \\
& & $55,2 \%$ Semi-antracito \\
& & $33.2 \%$ Antracito/Meta-antracito \\
\hline & \multirow{2}{*}{3,31} & $17,6 \%$ HVB B/A \\
& & $14 \%$ MVB \\
& & $6,8 \%$ Semi-antracito \\
& $61,6 \%$ Meta-antracito \\
\hline
\end{tabular}

$\mathrm{Rr}$ médio= valor médio da refletância aleatória das vitrinitas; Contaminantes: HVB B/A: betuminoso altovolátil $B / A ; M V B / L V B$ : betuminoso médiovolátil/ betuminoso baixo volátil

* Contribuição técnica ao 44ํ Seminário de Redução de Minério de Ferro e Matérias-primas, 15ำ Simpósio Brasileiro de Minério de Ferro e 2º Simpósio Brasileiro de Aglomeração de Minério de Ferro, 15 a 18 de setembro de 2014, Belo Horizonte, MG, Brasil. 


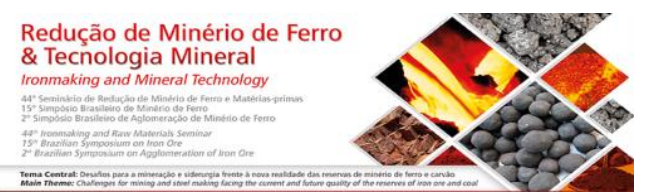

Tabela 5 -Umidade das amostras de combustíveis

\begin{tabular}{|c|c|c|c|}
\hline Amostra & Superficial (\%) & Inerente (\%) & Total (\%) \\
\hline A & 8,16 & 1,67 & 9,63 \\
\hline B & 6,73 & 3,00 & 9,22 \\
\hline
\end{tabular}

Tabela 6 - Análises química e física das amostras de combustíveis

\begin{tabular}{|c|c|c|c|}
\hline \multicolumn{2}{|c|}{ Item de Avaliação } & A & B \\
\hline \multirow{2}{*}{$\begin{array}{c}\text { Análise } \\
\text { Imediata }\end{array}$} & Matéria Volátil (\%) & 11,18 & 9,33 \\
\cline { 2 - 4 } & Cinza (\%) & 16,15 & 11,61 \\
\cline { 2 - 4 } & Carbono fixo (\%) & 72,67 & 79,05 \\
\hline HGI & - & 45 & 41 \\
\hline
\end{tabular}

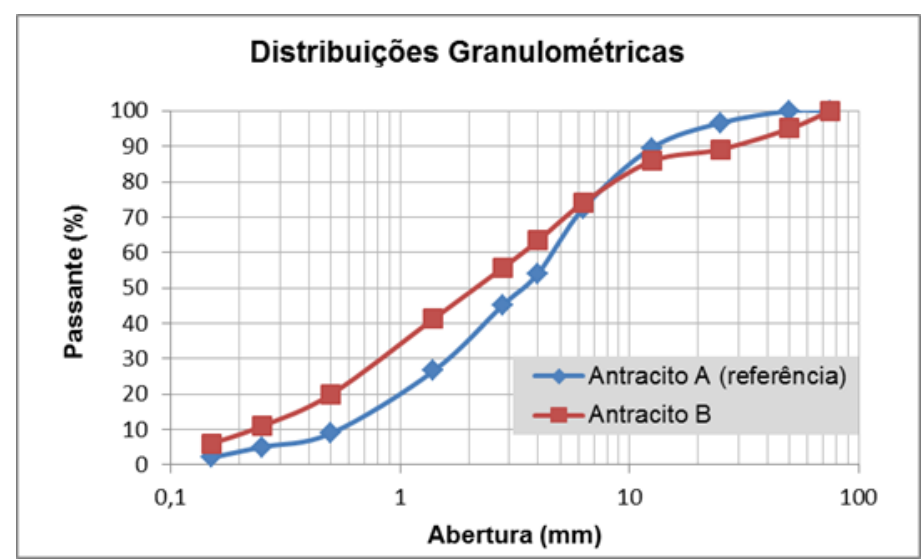

Figura 7 - Distribuição granulométrica das amostras de combustíveis.

Nota-se nas tabelas que o antracito $B$, que apresentou problemas de manuseio, diferese do A com relação ao seguinte:

$\checkmark$ Maior contaminação com carvões betuminosos;

$\checkmark$ Maior umidade inerente;

$\checkmark$ Maior teor de finos abaixo de 6,35 $\mathrm{mm}$.

As contaminações dos antracitos com carvões betuminosos podem afetar a sua capacidade de absorção de água ou a umidade inerente e, também, a superficial. Como pode ser observado na Figura 8, há uma redução da quantidade de poros e da capacidade de absorção de água a partir dos linhitos (teor de carbono $<75 \%$ ) até os semi-antracitos (teor de carbono 90\%) antes de aumentar mais suavemente para teores de carbono maiores, o que corresponde à classe dos antracitos e meta antracitos (teor de carbono $>90 \%$ ). A umidade inerente contida nos poros maiores se comporta como umidade superficial o que pode dificultar ainda mais o manuseio?.

* Contribuição técnica ao 44ํ Seminário de Redução de Minério de Ferro e Matérias-primas, 15ำ Simpósio Brasileiro de Minério de Ferro e 2 Simpósio Brasileiro de Aglomeração de Minério de Ferro, 15 a 18 de setembro de 2014, Belo Horizonte, MG, Brasil. 


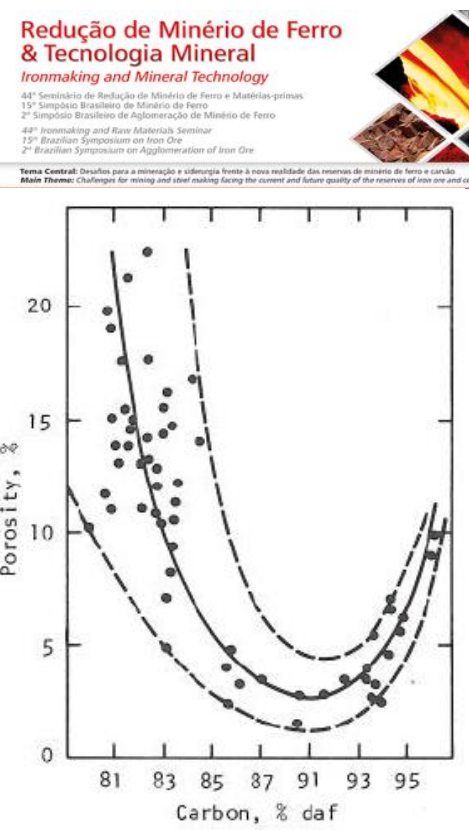

(a)

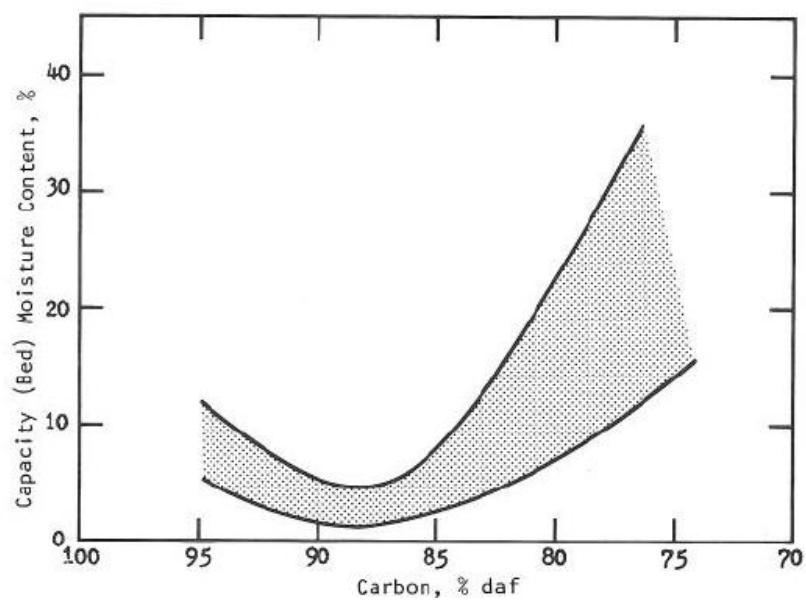

(b)

Figura 8 - (a) Relação entre porosidade e rank; (b) relação entre capacidade de absorção de água e rank [8].

O HGl é o teste que mede a facilidade com que um carvão pode ser moído. Os índices são expressos em números que variam entre 30 e 110 e, quanto mais elevados o valor do HGl, maior a facilidade de pulverização do carvão. Na Figura 9 é possível ver a relação entre $\mathrm{HGl}$ e a matéria volátil. Observa-se que carvões médios voláteis (entre 20 e $30 \%$ de matéria volátil) são os que apresentam maior $\mathrm{HGl}$, ou seja, antracitos mais contaminados com carvões betuminosos teriam maior tendência a serem também mais finos, como também foi observado. O efeito da umidade sobre o manuseio é maximizado pelo afinamento do material.

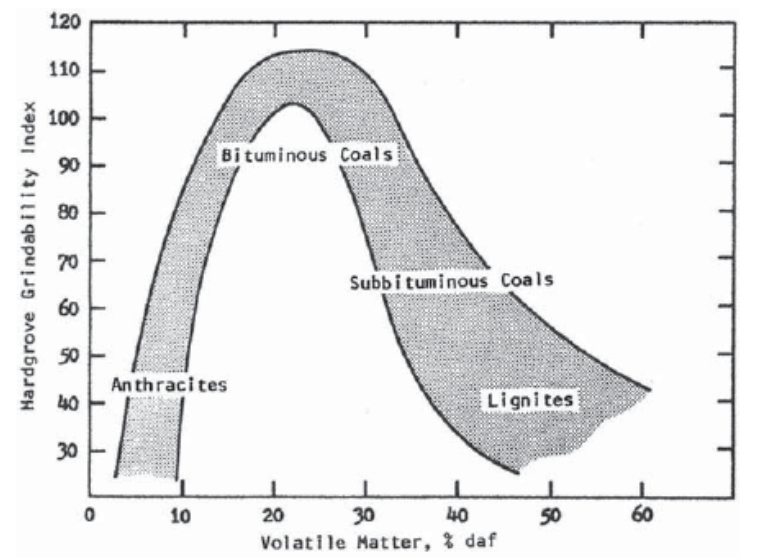

Figura 9 - Relação entre HGI e a matéria volátil [7].

Outro parâmetro que pode afetar o manuseio dos combustíveis é a composição mineral. A presença de certos argilo-minerais nos combustíveis pode acabar impactando negativamente 0 seu manuseio. Os argilo-minerais são, fundamentalmente, silicatos hidratados de alumínio representados pelas fases: caulinitas, ilitas e montmorilonitas [9]. Materiais carbonosos com maior participação de argilo-minerais apresentam problemas de preparação, pois elas incham na presença de água. Nos antracitos, em que o xisto é endurecido e bem compactado, observa-se um mínimo de desintegração, enquanto argilas e xistos em carvões de baixo rank, tais como os sub-betuminosos, apresentam um máximo de desintegração [10]. 
As Tabelas 7 e 8 mostram o resultado da difratometria por faixa granulométrica de amostras de combustíveis in natura e das suas cinzas. As áreas marcadas destas tabelas indicam a presença do mineral e as não marcadas a ausência.

Tabela 7 - Análises de DRX das amostras in natura dos antracitos

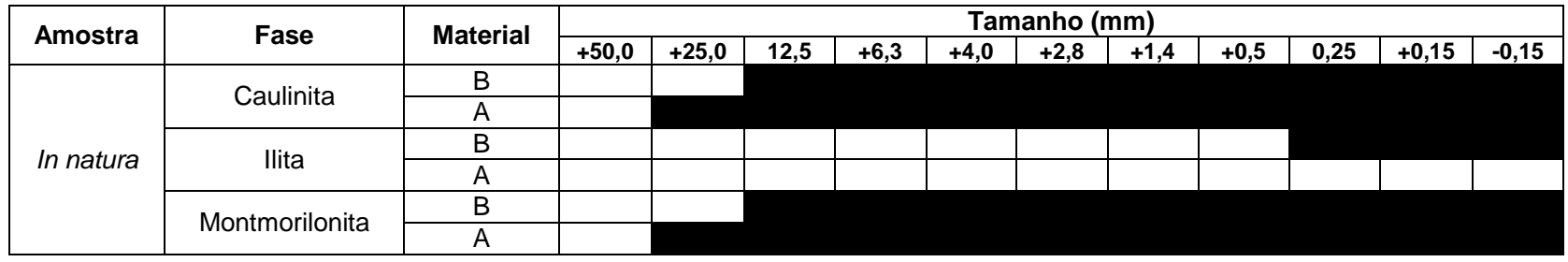

Tabela 8 - Análises de DRX das amostras das cinzas dos antracitos

\begin{tabular}{|c|c|c|c|c|c|c|c|c|c|c|c|c|c|}
\hline \multirow{2}{*}{ Amostra } & \multirow{2}{*}{ Fase } & \multirow{2}{*}{ Material } & \multicolumn{10}{|c|}{ Tamanho (mm) } & \\
\hline & & & $+50,0$ & $+25,0$ & 12,5 & $+6,3$ & $+4,0$ & $+2,8$ & $+1,4$ & $+0,5$ & 0,25 & $+0,15$ & $-0,15$ \\
\hline \multirow{6}{*}{ Cinzas } & Caulinita & $B$ & & & & & & & & & & & \\
\hline & \multirow{2}{*}{ llita } & $B$ & & & & & & & & & & & \\
\hline & & A & & & & & & & & & & & \\
\hline & \multirow{2}{*}{ Montmorilonita } & B & & & & & & & & & & & \\
\hline & & A & & & & & & & & & & & \\
\hline & Cristobalita & $\frac{B}{A}$ & & & & & & & & & & & \\
\hline
\end{tabular}

Nota-se nas tabelas que:

1. Em relação à caulinita e montomorilonita:

- As amostras in natura para os dois combustíveis indicam presença de caulinita e montmorilonita em quase todas as faixas de tamanho enquanto nas cinzas estas fases não foram identificadas. Isto ocorreu devido ao fato das cinzas terem sido obtidas a partir da combustão completa da amostra in natura a $725^{\circ} \mathrm{C}$ $\pm 25^{\circ} \mathrm{C}$. Neste processo, a caulinita e cristobalita sofrem alterações químicas e mineralógicas: a caulinita se transforma em metacaulinita amorfa, mulita e cristobalita em torno de $500^{\circ} \mathrm{C}$ e a montmorilonita, em cristobalita, mulita, espinélio e óxidos de ferro entre 800 e $1000^{\circ} \mathrm{C}[11,12]$.

- As cinzas do combustível B diferem-se da do A por indicarem a presença de cristobalita e mulita produtos da transformação de fase da caulinita e montmorilonita, sugerindo que esta amostra de combustível in natura conteria maior quantidade destas fases.

2. Em relação à ilita:

- A transformação da ilita ocorre somente por volta de $950^{\circ} \mathrm{C}$ formando metailita amorfa, mulita e cristobalita, ou seja, ela seria a única fase estável no processo de obtenção das cinzas a partir das amostras in natura [11,12].

- Nas amostras in natura a ilita somente foi detectada no combustível B enquanto nas cinzas ela foi detectada nos dois combustíveis em quase todas as faixas de tamanho. Isto ocorreu devido ao fato da presença de picos superpostos, além do intenso pico amorfo da matéria orgânica na amostra in natura ter dificultado a identificação desta fase. De qualquer maneira, isto não impediu a detecção de illita na amostra in natura do combustível B, sugerindo que ela estaria presente em maior quantidade e concentrada principalmente na fração fina desse combustível.

Resumindo, os resultados das análises difratométricas das amostras de combustíveis in natura e das suas cinzas sugerem que o combustível $\mathrm{B}$, o mais contaminado com carvões minerais, conteria maior quantidade de argilo-minerais, caulinita, montmorilonita e ilita, o que poderia implicar em dificuldades ainda maiores de manuseio e preparação deste combustível.

* Contribuição técnica ao 44 Seminário de Redução de Minério de Ferro e Matérias-primas, 15ำ Simpósio Brasileiro de Minério de Ferro e 2º Simpósio Brasileiro de Aglomeração de Minério de Ferro, 15 a 18 de setembro de 2014, Belo Horizonte, MG, Brasil. 


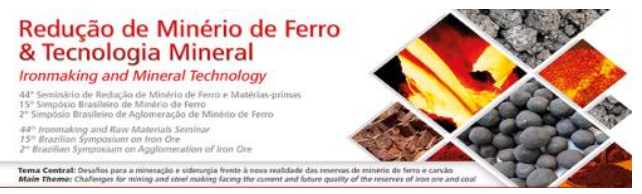

\section{CONCLUSÕES}

As contaminações de antracito com carvões minerais, mesmo que atendidas as especificações de material volátil, pode ter impacto importante sobre o desempenho do combustível durante o seu manuseio e preparação e o processo de queima da pelota. Um parâmetro petrográfico importante e que pôde ser relacionado com o desempenho do combustível no processo de queima da pelota foi o rank-variância da mistura, ou seja, isto sugere a necessidade de incluir este parâmetro para o controle de qualidade do combustível sólido utilizado pela Vale nas suas unidades de pelotização.

\section{REFERÊNCIAS}

1 Boechat FO, Pereira PM, Simões HO, Passigatti VP, Magnago DL, Bailon AMG, Moreira JL. Influência da Distribuição Granulométrica do Calcário e Carvão na Qualidade Física e Metalúrgica das Pelotas de Minério de Ferro. In: 41ํ Seminário de Redução de Minério de Ferro e Matérias-primas e 12ํㅗㄴ Seminário Brasileiro de Minério de Ferro, 2011.

2 Fonseca MC, Ferreira HS, Otaviano MM, Perin V. Influência da Dosagem de Carvão na Qualidade das Pelotas Queimadas. In: 39 Seminário de Redução de Minério de Ferro e Matérias-primas e 10 Seminário Brasileiro de Minério de Ferro, 2009.

3 Casagrande C, Mafra W, Vilela ACF, Osorio E, Ghiggi MLF. Influence of different types of solid fuels on the quality of iron ore pellets. In: 3rd International Meeting on Ironmaking and 2nd International Symposium on Iron Ore, 2008, Sao Luis City, Maranhão State, Brazil. São Paulo: ABM, 2008. p. 480-488.

4 Machado J, Nascimento L, Maranha S, Pereira R, Tolentino J, Mafra W. Analyses of Solid Fuels in the Pelletizing Process: The Use of Different Coal Characterization Techniques. In: 6th International Congress of the Science and Technology of Ironmaking - ICSTI, 2012.

5 Alonso MJG, Borrego AG, Álvarez D, Kalkreuth W, Menéndez R.. Physicochemical transformations of coal particles during pyrolysis and combustion. Fuel, 2001; 80: 18571870.

6 International Organization for Standardization, BS ISO 4700:2007: Iron ores - Determination of tumble strength, Third edition, London, November 1995.

7 Riley JT. Routine Coal and Coke Analysis: Collection, interpretation, and use of Analytical Data. ASTM Stock $n^{\circ}$ MNL57. 1942

8 Berkowitz N. Na Introduction to Coal Technology. Academic Press Limited. London, 1994.

9 DavillaC.ftp://ftp.cefetes.br/cursos/Transportes/CelioDavilla/Solos/Literatura\%20complement ar/Notas\%20de\%20aula/unidade_4.pdf

10 Leonard JW. Coal Preparation. The American Institute of Mining Metallurgical, and Petroleum Engineers, Inc. new York, 1979.

11 Vassilev SV, Vassileva CG. Ocurrence, abundace and oringun of minerals in coals and coal ashes, Fuel Processing Technology, v. 48, p. 85-106, 1996.

12 Vassileva CG, Vassilev SV. Behaviour of inorganic matter during heating of Bulgarian coals - 1. Lignites, Fuel Processing Technology, 2005; 86: 1297-1333.

* Contribuição técnica ao 44ํㅗ Seminário de Redução de Minério de Ferro e Matérias-primas, 15ำ Simpósio Brasileiro de Minério de Ferro e 2 Simpósio Brasileiro de Aglomeração de Minério de Ferro, 15 a 18 de setembro de 2014, Belo Horizonte, MG, Brasil. 